GEOPHYSICAL RESEARCH LETTERS, VOL. 17, NO. 7, PAGES 1001-1004, JUNE 1990

\title{
RUPTURE PROCESS AND STRESS-DROP OF THE GREAT 1989 MACQUARIE RIDGE EARTHQUAKE
}

\author{
Bart W. Tichelaar and Larry J. Ruff
}

Department of Geological Sciences, The University of Michigan

\begin{abstract}
On May 23, 1989, a great $\left(\mathrm{M}_{\mathrm{W}}=8.1\right)$ earthquake occurred in the Macquarie Ridge complex, south of New Zealand. The earthquake is one of the largest in the Macquarie Ridge complex this century, and represents the right-lateral strike-slip component of the motion between the Pacific plate and the Australian plate. Subduction initistion appears to be presently occurring in the Macquarie Ridge complex, and it has been suggested that plate boundary strike-slip earthquakes in a transitional tectonic environment have a high stress-drop. We have investigated the source rupture process of the 1989 earthquake, using teleseismic $P$ and $S H$ waves. The best point source depth is $12 \mathrm{~km}$ below the ocean bottom. The deconvolved source ime function is dominated by a single pulse with a large moment release $\left(1.8 \times 10^{21} \mathrm{Nm}\right)$ and a short duration $(20 \mathrm{~s})$. The moment rate increases slowly in the first $10 \mathrm{~s}$ of the rupture process, and is suddenly truncated at $20 \mathrm{~s}$. There is no resolvable directivity to this sharp truncation, which given the temporal resolution of the data set, means that the spatial location of the sharp truncation is within approximately $50 \mathrm{~km}$ of the epicenter. The stress-drop and average displacement may be as high as 370 bars and $36 \mathrm{~m}$. These values are unusually high, and strongly support the suggestion that high stress-drop earthquakes are characteristic for transitional tectonic environments.
\end{abstract}

\section{Introduction}

The Macquarie Ridge complex forms the boundary between the Pacific plate and the Australian plate, and runs from New Zealand southward to the Pacific-AustraliaAntarctica triple junction. Its tectonic environment is characterized by rapid evolution, and has changed from a tensional environment in the Oligocene, to strike-slip with a compressional component since the Miocene [Molnar et al., 1975]. This rapid evolution is the result of the southward migration of the Pacific-Australia rotation pole, which is locared close to the Macquarie Ridge complex [Walcott, 1978]. The current tectonic setting is oblique convergence with an increasing thrust component going northward from the triple junction, and the topographic expression is an alternation of troughs and rises (Figure 1). Subduction initiation appears to be presently occurring [Ruff et al., 1989], which is reflected by the seismicity in the region. The seismicity in the Macquarie Ridge consists of numerous low-angle thrust earthquakes, but most of the seismic mo-

Copyright 1990 by the American Geophysical Union.

Paper number 90GL00749

$0094-8276 / 90 / 90 G L-00749 \$ 03.00$ ment is released in a few great strike-slip earthquakes (Figure 1). This combination of thrust earthquakes with a few great strike-slip earthquakes is characteristic for the transitional tectonic environment of the Macquarie Ridge complex [see Ruff et al., 1989].

The great Macquarie Ridge earthquake $\left(M_{W}=8.1\right)$ of 23 May 1989 occurred in the central section of the Macquarie Ridge Complex. It is the largest earthquake recorded anywhere in the last decade, and the largest well-recorded earthquake in the Macquarie Ridge region. Its focal mechanism (Figure 2) represents right lateral strike-slip on a plane that strikes in the local direction of the plate boundary. Its epicenter is located west of a small trench (Figure 1). Two smaller thrust earthquakes $(M<6.5)$ have occurred in the same section of the ridge since 1966 (Figure 2). The thrust earthquakes are consistent with westward subduction of the Pacific plate beneath Australia, which agrees with the location of the oceanic trench relative to a bathymetric high in the ocean floor. About $500 \mathrm{~km}$ further to the north, the great 25 May $1981 \mathrm{M}_{\mathrm{W}}=7.7$ right lateral strike-slip earthquake [Ruff et al., 1989] occurred in the northern section of the ridge. This region is similar to the 1989 region,

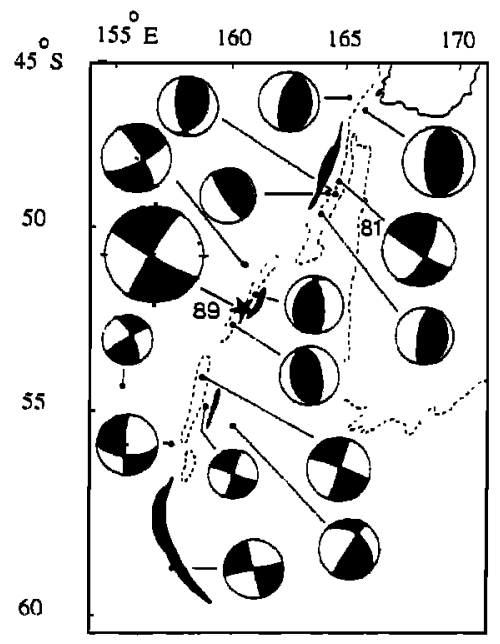

Fig. 1. Reliable focal mechanisms for post-1963 earthquakes in the Macquarie Ridge complex. The size of the focal sphere is proportional to event magnitude. The star is the epicenter of the 1989 earthquake. The dashed lines are the 1000 fathom depth contours (bathymetric high), and the oceanic troughs, as defined by the 2600 fathom depth contour, are shaded. Part of South Island, New Zealand, can be seen in the upper right corner. The oblique convergence between the Australian plate (west of the ridge) and the Pacific plate (east of the ridge) causes both strike-slip and thrust earthquakes. (After Ruff et al., 1989.) 


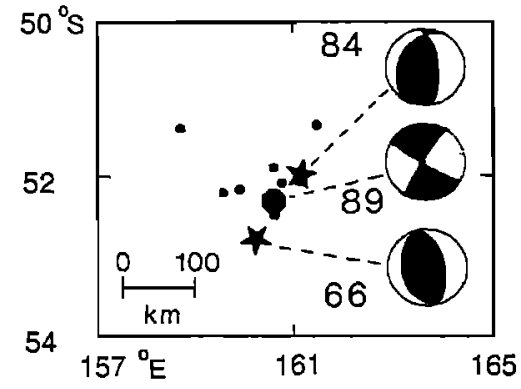

Fig. 2. Focal mechanism of the 1989 earthquake (solid circle), together with the mechanisms of the two smaller thrust earthquakes (25 May 1966, M=6.5 and 23 May 1984, $\mathrm{M}=5.9$; shown as stars). The 1-day aftershocks of the 1989 event (PDE locations) are shown as dots.

in the sense that all earthquakes between 1964 and 1981 are smaller than the great 1981 event and represent thrusting. The Australian plate appears to be subducting beneath the Pacific plate in the 1981 region. The 1981 earthquake had a stress-drop of more than 80 bars [Ruff et al., 1989], which is very high for interplate strike-slip events [see Kanamori and Anderson, 1975]. Another example of a high stress-drop strike-slip event in a transitional tectonic regime is the North-Atlantic earthquake of 26 May 1975 $\left(M_{W}=7,8\right)$ [Lynnes and Ruff, 1985]. Our purpose is to study the rupture process of the 1989 earthquake, and interpret our results in both the regional and global context.

\section{Body waves for the Macquarie Ridge earthquake}

To determine focal parameters and to study the rupture process, we have collected $P$ and $S H$ wave recordings for the 1989 earthquake. These body waves were recorded on various instruments, ranging from SRO seismographs, long period instruments of the new Chinese Digital Seismographic Network (CDSN) and long period DWWSSN instruments, to broadband GEOSCOPE [Romanowicz et al., 1984] stations and short period instruments of the DWWSSN and CDSN networks. Figures 1 and 2 show the focal mechanism, which is interpreted as right lateral strike-slip on a near vertical NE-SW striking plane. Figure 2 also shows the 1-day PDE aftershock locations. While most of the aftershocks are clustered within $60 \mathrm{~km}$ of the mainshock epicenter, there are two aftershocks at more than $100 \mathrm{~km}$ away in orthogonal directions.

Inversion of the body waves for the source time function [Ruff, 1989] clearly shows a dominant pulse in the first $20 \mathrm{~s}$. In addition, the individual time functions for different azimuths are quite similar, which suggests that the directivity associated with this dominant pulse is smaller than a few seconds. Because of the absence of significant directivity, we can deconvolve the overall best source time function from a set of azimuthally well-distributed $P$ and $S H$ waves. To formally account for the scaling incompatibility between the seismograms, we used omnilinear inversion [Ruff, 1989; Tichelaar and Ruff, 1990]. The heterogeneous mixture of digital instrumentation presents another practical difficulty. Fortunately, this difficulty is easily removed by use of internal data weighting that equalizes the instrument responses in the passband of 10-30 s. Figure 3

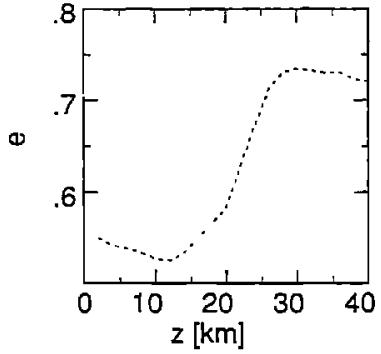

Fig. 3. Error parameter, e, as a function of assumed point source depth, $z$, for the data set of Figure 4, where e is the ratio of the lengths of the misfit vector and the data vector.

shows the error parameter as a function of assumed point source depth. A point source at $12 \mathrm{~km}$ below the ocean bottom ( $v_{p}=6.7 \mathrm{~km} / \mathrm{s}$, Poisson's ratio of $\left.0.25, \rho=2.7 \mathrm{~g} / \mathrm{cm}^{3}\right)$ gives the best fit to the data. The sensitivity of the body waveforms to focal depth results mainly from the addition of broadband GEOSCOPE $P$ and $S H$ phases to the data set. Figure 4 shows the source time function for the best depth of $12 \mathrm{~km}$, together with the seismograms. While omnilinear inversion allows us to include diffracted $P$ waves in Figure 4, we only use the non-diffracted phases for mo-

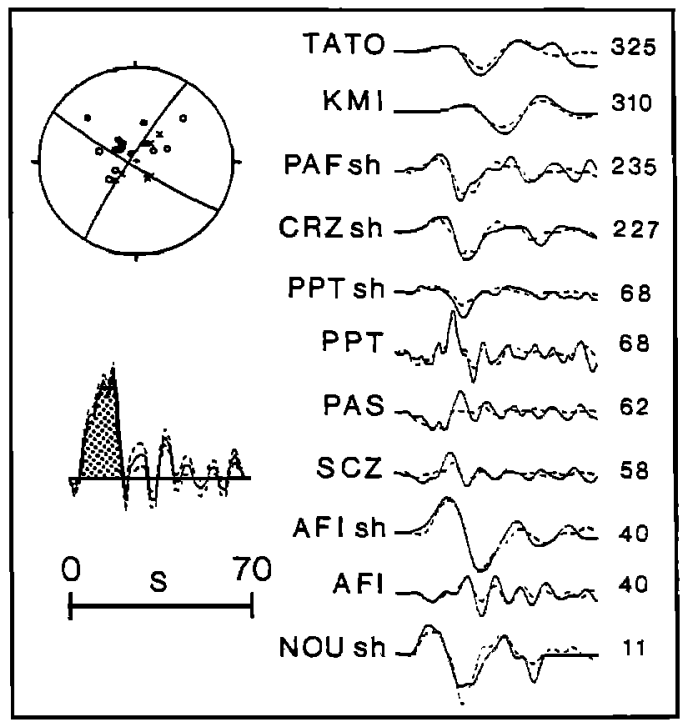

Fig. 4. First motion data (upper left) plotted together with the focal mechanism from the body wave forms (strike $212^{\circ}$, dip $85^{\circ}$, slip $185^{\circ}$ ). Solid circles are compressional, open circles dilatational, and crosses are nodal arrivals. The source time function (lower left) is basically a single event, and was obtained by deconvolution of 11 body wave phases (right) for a point source Green's function at a depth of $12 \mathrm{~km}$ in a half space, with a $3 \mathrm{~km}$ water layer on top; the two dashed lines represent one standard deviation around the mean. Data (solid traces) are labeled with the station names on the left and source-station azimuth $(\%$ on the right. The data set consists of vertical $P$ waves (no suffix to station name), and tangential $S H$ waves (suffix "sh"). Dashed traces are synthetic seismograms. The seismograms show the correct relative amplitudes after applying the internal data weighting (see text). 
ment estimation. As can be seen from this figure, most of the seismic moment was released within $20 \mathrm{~s}$, during one single event of moment release. The basic features of the source time function are that the moment rate increases slowly to its maximum during the first $10 \mathrm{~s}$ of the rupture process, remains high for another 8 to 10 seconds, and then suddenly drops back to zero. The seismic moment that was released in these $20 \mathrm{~s}$ is $1.8 \times 10^{21} \mathrm{Nm}\left(\mathrm{M}_{\mathrm{W}}=8.1\right)$. It is possible that there is some minor moment release after $20 \mathrm{~s}$. Also, the body waveforms prefer a focal mechanism (Figure 4) that is inconsistent with a few first motions around the nodal planes, which indicates that there might have been a slight change of focal mechanism during the rupture process. While this change in focal mechanism is seismologically interesting, it is not tectonically significant.

The truncation of moment release at approximately $20 \mathrm{~s}$ is so sharp that it should be possible to directly observe the truncation in the seismograms. To look for any discernable directivity, we have measured the time of the truncation directly from seismograms; we use both short period and broadband $P$ wave recordings. Figure 5 shows these recordings, together with the time picks that we have made. Many instruments recorded a distinct arrival at 18 to $20 \mathrm{~s}$, with a polarity opposite from the first $P$ arrival. A directivity analysis shows that the distance and timing of the tuncation is $11 \pm 40 \mathrm{~km}$ and $19 \pm 2 \mathrm{~s}(2 \sigma)$, with respect to the epicenter. The standard errors $\sigma$ are determined for an a priori standard error in the time picks of $3 \mathrm{~s}$, which is mainly due to the emergent first arrival. There is no resolvable directivity for the truncation, thus the truncation is located close to the epicenter. A conservative statement is that the truncation of moment release occurred probably not further than $50 \mathrm{~km}$ away from the epicenter.

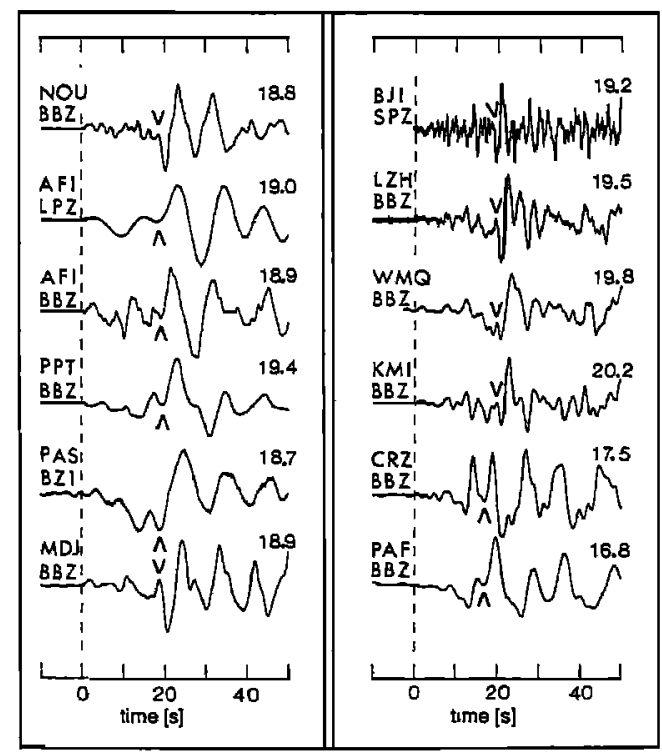

Fig. 5. Short period and broadband vertical components show a distinct arrival (arrow head) of polarity opposite to the first arrival (AFI is near-nodal). Data are lined up on the arrival of the $P$ wave (dashed line). Numbers above the traces are the timing of this arrival (the truncation phase), relative to $P$ arrival (in seconds). The records are for displacement, except NOU and CRZ, where we show the velocity records.

\section{Stress-drop}

The stress-drop for the 1989 Macquarie Ridge earthquake can be estimated from the seismic moment, together with fault width and fault length (or, alternatively, fault radius). While the seismic moment is determined directly from the body waves, it is more difficult to estimate the fault dimensions. Because of the lack of resolvable directivity, the basic constraint on fault dimensions comes from the time function duration (about $20 \mathrm{~s}$ ). We now need to assume a rupture model and a rupture velocity. The rupture model that maximizes the fault area, and thus minimizes the stress-drop, is the circular model; rupture nucleates at depth and propagates for $20 \mathrm{~s}$ in all directions. For this rupture model, we find a stress-drop of 70 bars and an average displacement of $6 \mathrm{~m}$, using the stress-drop formula for a buried circular fault and assuming a rupture velocity of $2.5 \mathrm{~km} / \mathrm{s}$. However, the fault width (or depth extent) for this rupture model would be $100 \mathrm{~km}$, which would give a centroid depth of $50 \mathrm{~km}$. A fault width of $25 \mathrm{~km}$ is more realistic, given the best point-source depth of $12 \mathrm{~km}$ (Figure 3). The sudden truncation of moment release can be explained either by a barrier that "arrests" the rupture process, or by a sudden transition to a "weak" zone, where litthe co-seismic slip occurs. For the circular rupture model, it is difficult to explain the observed sharp truncation of moment release at 20 s: rupture would be suddenly truncated all along the circular rupture front at the same time. If rupture is confined to a region that extends from $25 \mathrm{~km}$ depth to the surface, then the stress-drop and displacement are 185 bars and $18 \mathrm{~m}$ for bilateral rupture, and 370 bars and $36 \mathrm{~m}$ for unilateral rupture, using the stress-drop formula for an infinitely long strike-slip fault that reaches the surface. In both cases, the stress-drop and displacement are very high for interplate strike-slip events [see Kanamori and Anderson, 1975], which makes the 1989 Macquarie Ridge earthquake an anomalous event. We prefer the unilateral rupture model, because it requires the sharp truncation to be located at only one side of the epicenter.

The great 1981 Macquarie Ridge earthquake also has a high stress-drop: 80 bars [Ruff et al., 1989]. Another great strike-slip earthquake, the 26 May 1975 North Atlantic earthquake $\left(\mathrm{M}_{\mathrm{W}}=7.8\right)$, has a stress-drop estimate of 140 bars, and Lynnes and Ruff [1985] proposed that this earthquake also occurred in a transitional tectonic regime. In contrast, the 4 February 1976 Guatemala earthquake $\left(M_{W}=7.6\right)$ occurred in a continental setting with a much smaller stress-drop of 30 bars [Kanamori and Stewart, 1978]. The 30 July 1972 Sitka, earthquake $\left(M_{W}=7.6\right)$ occurred on the stable Pacific-North America plate boundary with a fault averaged stress-drop of 100 bars [see Schell and Ruff, 1989]. Figure 6 compares various strike-slip events on the basis of rupture length and moment, and hence shows relative values of stress-drop. It seems that the 1989 Macquarie Ridge earthquake is another example of a high stress-drop event in a transitional tectonic environment. In fact, the 1989 Macquarie Ridge event may have the highest stress-drop for any great earthquake.

\section{Conclusions}

The Macquarie Ridge earthquake of 23 May 1989 released seismic moment of $1.8 \times 10^{21} \mathrm{Nm}$ in a single 


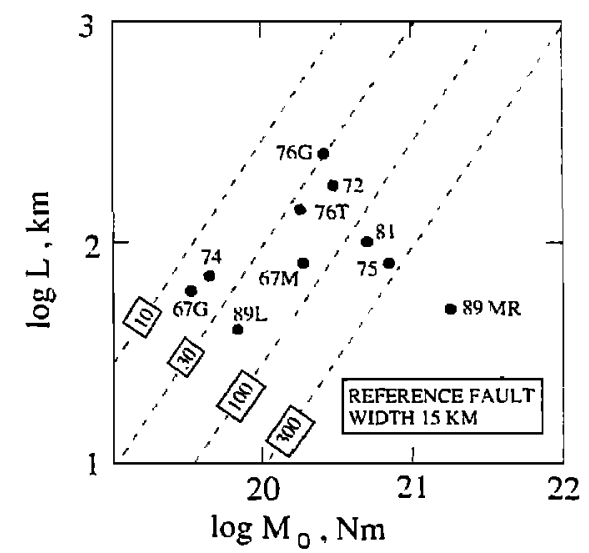

Fig. 6. Rupture length as a function of seismic moment for large strike-slip earthquakes (dots). Lines of equal stressdrop are dashed, calculated for a fault width of $15 \mathrm{~km}$, and are labeled with the stress-drop value in bars. $76 \mathrm{G}=$ Guatemala event; 72, Sitka earthquake [Schell and Ruff, 1989]; 76T, 1976 Tangshan, earthquake [Butler et al., 1979]; 67M, 1967 Mudurnu Valley, Turkey, earthquake [Stewart and Kanamori, 1982]; 67G and 74, 1967 and 1974 Gibbs fracture zone earthquakes [Kanamori and Stewart, 1976]; and 89L, 1989 Loma Prieta earthquake [Plafker and Galloway, 1989]. Note that the 1989 Macquarie Ridge earthquake (89MR) has the highest stress-drop.

event with a short rupture time (20 s). The source time function shows a sharp truncation of the moment release at $20 \mathrm{~s}$. It is possible that minor moment release occurred after this dominant pulse. We did not resolve directivity associated with the sharp truncation of moment release. This implies that most of the seismic moment was released within $50 \mathrm{~km}$ from the epicenter. The stress drop and average displacement of the 1989 earthquake are very high, and may well have been 370 bars and $36 \mathrm{~m}$. This unusually high stress-drop seems to be diagnostic for strike-slip environments along transitional plate boundaries.

Acknowledgments. This research was supported by NSF grant EAR8720935 to LJR.

\section{References}

Butler, R., G.S. Stewart, and H. Kanamori, The July 27, 1976 Tangshan, China, earthquake - a complex sequence of intraplate events, Bull. Seism. Soc. Am., 69, 207-220, 1979.

Kanamori, H., and D.L. Anderson, Theoretical basis of some empirical relations in seismology, Bull. Seism. Soc. Am., 65, 1073-1095, 1975.
Kanamori, H., and G.S. Stewart, Mode of strain release along the Gibbs fracture zone, Mid-Atlantic ridge, Phys. Earth Planet. Int., 11, 312-332, 1976.

Kanamori, H., and G.S. Stewart, Seismological aspects of the Guatemala earthquake of February 4, 1976, J. Geophys. Res., 83, 3427-3434, 1978.

Lynnes, C.S., and L.J. Ruff, Source process and tectonic implications of the great 1975 North Atlantic earthquake, Geophys. J. R. Astr. Soc., 82, 497-510, 1985.

Molnar, P., T. Atwater, J. Mammerickx and S.M. Smith, Magnetic anomalies, bathymetry, and the tectonic evolution of the south Pacific since the late Cretaceous, Geophys. J. R. Astr. Soc., 40, 383-420, 1975.

Plafker, G., and J.P. Galloway, editors, Lessons learned from the Loma Prieta, California, earthquake of October 17, 1989, U.S. Geological Survey, circular 1045, Govern. Print. Office, Washington, D.C., 48 pp., 1989.

Romanowicz, B., M. Cara, J.F. Fels, and D. Rouland, GEOSCOPE: A French initiative in long-period three component seismic networks, Eos Trans. AGU, 65, $753,1984$.

Ruff, L.J., Multi-trace deconvolution with unknown trace scale factors: Omnilinear inversion of $P$ and $S$ waves for source time functions, Geophys. Res. Lett., 16, 1043-1046, 1989.

Ruff, L.J., J.W. Given, C.O. Sanders, and C.M. Sperber, Large earthquakes in the Macquarie Ridge complex: Transitional tectonics and subduction initiation, Pageoph, 129, 71-130, 1989.

Schell, M.M., and L.J. Ruff, Rupture of a seismic gap in southeastem Alaska: the 1972 Sitka earthquake (MS 7.6), Phys. Earth Planet. Int., 54, 241-257, 1989.

Stewart, G.S., and H. Kanamori, Complexity of rupture in large strike-slip earthquakes in Turkey, Phys. Earth Planet. Int., 28, 70-84, 1982.

Tichelaar, B.W., and L.J. Ruff, Seismic coupling along the Chilean subduction zone, submitted to: $J$. Geophys. Res., 1990.

Walcott, R.I., Present tectonics and late Cenozoic evolution of New Zealand, Geophys. J. R. Astron. Sac., 52, 137-164, 1978.

B. Tichelaar and L. Ruff, Dept. Geological Sciences University of Michigan, Ann Arbor, MI 48109.

(Received February 9, 1990; accepted March 9, 1990.) 